\title{
Espécie nova de Cariblatta Hebard do Rio de Janeiro, Brasil (Blattaria, Blattellidae)
}

\author{
Sonia Maria Lopes ${ }^{1} \&$ Edivar Heeren de Oliveira ${ }^{1}$
} ${ }^{1}$ Departamento de Entomologia, Museu Nacional, Universidade Federal do Rio de Janeiro, Quinta da Boa Vista, $20940-040$ São Cristóvão-RJ,
Brasil. sonialf@acd.ufrj.br

\begin{abstract}
New species of Cariblatta Hebard from Rio de Janeiro, Brazil (Blattaria, Blattellidae). A new species of Cariblatta Hebard (C. grandiosa sp. nov.) from Rio de Janeiro is described. Illustrations of genitalia are presented.

KEYWORDS. Blattaria; description; taxonomy.

RESUMO. Espécie nova de Cariblatta Hebard do Rio de Janeiro, Brasil (Blattaria, Blattellidae). Uma nova espécie de Cariblatta Hebard (C. grandiosa sp. nov.) do Rio de Janeiro é descrita e as peças genitais são ilustradas.

PALAVRAS-CHAVE. Blattaria; descrição; taxonomia.
\end{abstract}

Cariblatta foi descrito por Hebard (1916). O gênero conta atualmente, com 67 espécies conhecidas distribuídas nas três Américas, com maior ocorrência na América Central e América do Sul.

Os espécimes desse gênero podem ser encontrados em diversos biótopos, como folhas secas, solo de floresta úmida, vegetação rasteira, gramíneas, bromélias epífitas, em brácteas de palmáceas e em bananeira. Muitas espécies são coletadas à noite, atraídas pela luz.

Em relação à genitália, as espécies de Cariblatta apresentam as placas subgenitais dos machos e respectivos estilos, com formas variadas e diversificadas, simétricos ou não. A forma e a disposição desses estilos e espinhos caracterizam as espécies. O material estudado encontra-se depositado no Museu Nacional, Universidade Federal do Rio de Janeiro (MNRJ).

\section{Cariblatta grandiosa $\mathbf{s p . ~ n o v . ~}$}

(Figs. 1-8)

Diagnose. A espécie distingue-se de todas as demais pela configuração da placa subgenital muito alargada, dos estilos diferenciados tanto na forma como no tamanho e do esclerito mediano em forma de cristas apicalmente.

Holótipo macho. Coloração geral castanho-amarelada brilhosa. Pronoto transparente com disco central amareloleitoso, apresentando manchas castanhas mais escuras, irregulares, dispostas principalmente na região látero-anterior do disco central (Fig. 2), e nas pernas na parte anterior das coxas, bases dos espinhos, ápices dorsais das tíbias e dos tarsos, e extremidades das unhas. Cabeça amarela e olhos negros (Fig. 1). Tégminas com tronco inicial de todas as nervuras castanho.

Dimensões (mm). Holótipo macho. Comprimento total 15,5; comprimento do pronoto 3,0; largura do pronoto 4,5; comprimento da tégmina 13,0; largura da tégmina 4,5.

Cabeça. Vértice levemente exposto, espaço interocular apicalmente amplo subigual em tamanho à área entre as bases das inserções antenais (Fig. 1); antenas longas, filiformes e ciliadas; palpos maxilares ciliados e desenvolvidos, com o primeiro e segundo artículos reduzidos e do terceiro ao quinto, decrescentes em tamanho, este último dilatado.

Tórax. Pronoto transverso e convexo apresentando abas laterais arredondadas. Pernas desenvolvidas e espinhosas; fêmur anterior, em sua face ântero-ventral, com uma série de quatro espinhos decrescendo gradativamente em tamanho, da região mediana em direção ao ápice, esse com três espinhos apicais maiores; face póstero-ventral com quatro espinhos espaçados na região médio-apical, todos do mesmo tamanho, sendo um deles apical; primeiro artículo tarsal grande maior em comprimento que a soma dos três seguintes, decrescentes em tamanho; quinto artículo menor que o primeiro, todos ciliados; pulvilos nos quatro artículos; arólios desenvolvidos; unhas simétricas e simples. Fêmures médio e posterior, em sua face ântero-ventral com oito espinhos grandes e espaçados, sendo um deles apical; face póstero-ventral com seis espinhos grandes e espaçados sendo um deles apical. Tégminas largas ultrapassando o ápice do abdome. Campo marginal levemente côncavo, base da nervura costal bem distinta; campo escapular reto até a base do campo discoidal, levemente convexo, que se apresenta curvo no ápice, formado por nervuras dispostas longitudinalmente. Asas com nervura costal simples, nervura radial bifurcada no terço basal, com oito ramos oblíquos, sendo os sete primeiros ramos dilatados apicalmente; nervura mediana com três ramos simples e longitudinais no terço mediano, seguindo bifurcada para o ápice. Nervura cubital bifurcada no terço basal e novamente no mediano. Nervuras axilares em número de oito ou mais. Triângulo apical pouco desenvolvido.

Abdome. Placa supra-anal ciliada (Fig. 3), pronunciada entre 


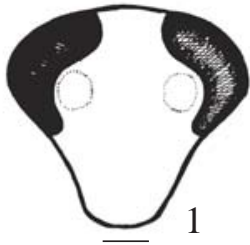

$0, \overline{5 \mathrm{~mm}}$

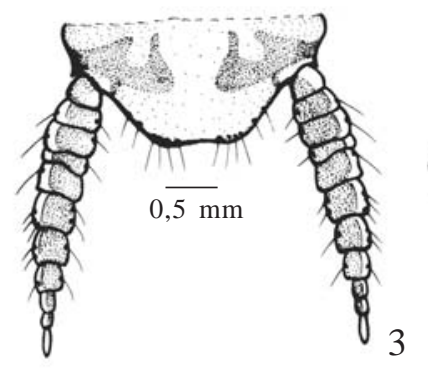

3

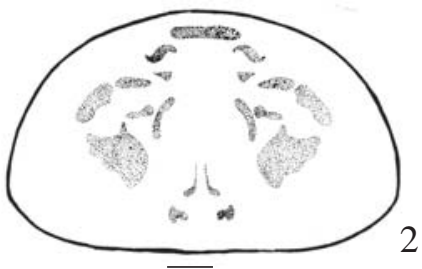

$0, \overline{5 \mathrm{~mm}}$

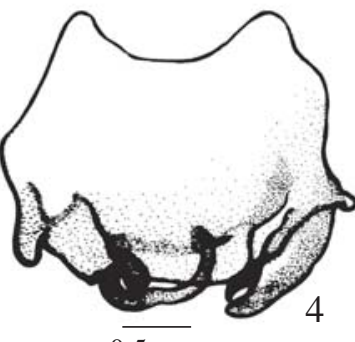

$\overline{0,5 \mathrm{~mm}}$

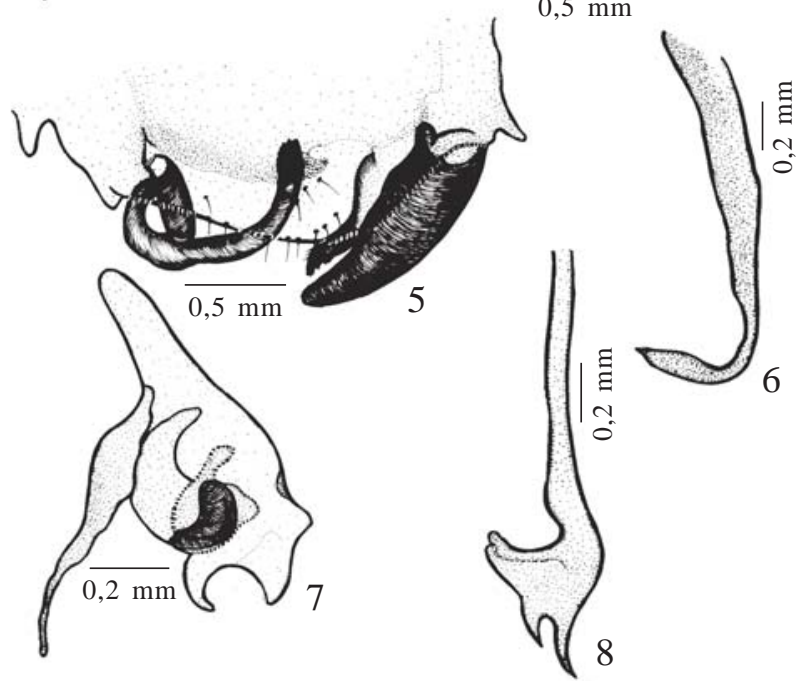

Figs. 1-8. Cariblatta grandiosa sp. nov. Holótipo macho: 1, Cabeça, vista ventral; 2, pronoto, vista dorsal; 3, placa supra-anal, vista dorsal; 4 , placa subgenital, vista ventral; 5 , estilos na placa subgenital, vista ventral; 6, falômero direito, vista dorsal; 7, falômero esquerdo, vista dorsal; 8 , esclerito mediano, vista dorsal. os cercos e com suave reentrância mediana, cercos desenvolvidos e ciliados, paraproctos evidenciados. Placa subgenital alargada com os bordos apicais distintos e com estilos diferenciados em forma e tamanho, estilo esquerdo delgado voltado para o centro da placa e com espinhos pequenos apicalmente, estilo direito mais largo, afilando para o ápice e ciliado. Presença de estilos acessórios entre aqueles citados anteriormente um deles muito desenvolvido e afilado e outro menor próximo ao maior estilo (Figs. 4 e 5). Falômero direito em forma de gancho (Fig. 6); falômero esquerdo em forma de $\mathrm{U}$ invertido, com uma das projeções laterais mais desenvolvida, medianamente com estrutura elipsóide esclerotinizada (Fig. 7); esclerito mediano evidenciado apicalmente em forma de duas cristas, uma mais desenvolvida que a outra (Fig. 8).

Etimologia. Grandis (grande) + osa. O nome da espécie é alusivo à configuração da placa subgenital e esclerito mediano, até então não visto nas demais espécies do gênero.

Material examinado. Holótipo macho. Brasil: Rio de Janeiro, Serra dos Órgãos, 29/08/1957, J. Becker col. (MNRJ).

Agradecimentos. Nossos agradecimentos ao Conselho Nacional de Desenvolvimento Científico e Tecnológico (CNPq) e Fundação de Amparo à Pesquisa do Estado do Rio de Janeiro (FAPERJ) pelo apoio financeiro ao Projeto de Pesquisas "Estudo de Blattaria Neotropical" realizado no Museu Nacional, Departamento de Entomologia.

\section{REFERÊNCIA}

Hebard, M. 1916. A new genus Cariblatta of the group Blattellites. Transactions of the American Entomological Society 42: 147186. 